\title{
Ulrike Schmieder, Nach der Sklaverei. Martinique und Kuba im Vergleich, Sklaverai und Postemanzipation, vol. 7, Berlin, Lit Verlag, 2014, 444 páginas ISBN 978-3-643-12356-5.
}

Javier Laviña Universitat de Barcelona

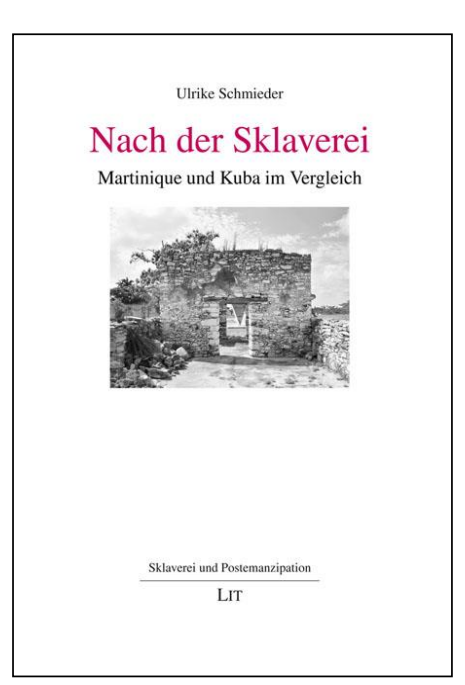

Ulrike Smieder nos ofrece un trabajo interesante sobre la situación de los ex esclavos en Cuba y Martinica tras la abolición.

El libro está dividido en 6 capítulos más uno final dedicado a las fuentes y la bibliografía sobre el tema.

La composición es buena y equilibrada en cada uno de los apartados. El primer capítulo lo dedica a la discusión esclavitud y capitalismo, clase social y esclavitud, en los que va respondiendo desde una metodología clara al debate y tomando posiciones en

el mismo.

Son especialmente interesantes los planteamientos que hace entre la criollización de los esclavos frente a los partidarios y seguidores de la presencia de cultura africana en América. El debate se inicia en los años treinta del siglo pasado y se prolonga hasta hoy con los trabajos de algunos especialistas en África como Lovejoy, Thorton; y otros especialistas en esclavitud en Brasil, Sweet, 
Alencastro, que defienden la presencia de cultura africana en América y los partidarios de la tesis de la criollización como Ira Berlin y Jane Landers.

La cuestión sigue abierta y en los dos casos encontramos argumentos de defensa. Las posiciones encontradas de ambas tesis se refieren también a espacios distintos, Brasil en el primer caso frente a Estados Unidos o el resto de América Latina.

Otra de las discusiones que se plantean es la tesis de Paterson, sobre la muerte social del esclavo, tesis frente a la que la autora presenta toda una muestra de estudios que argumentan la tesis contraria, había una economía de los esclavos, una familia esclava, una organización social y una resistencia a la esclavitud que hubiera sido imposible plantear desde "la muerte social del esclavo".

Otro de los puntos que la autora trata y resuelve de forma excelente es la cuestión de la familia esclava, donde utiliza no sólo la bibliografía más actualizada sobre la cuestión si no que aporta datos de sus investigaciones anteriores, centradas en Cuba: La confirmación de la existencia de una familia esclava, que no quiere decir que esta tuviera que seguir las pautas marcadas por los estamentos oficiales de los propietarios. En el trabajo se van dando ejemplos de cómo se construye y reconstruye la familia esclava, y de cómo se entiende la cuestión de género que también resuelve en el primer capítulo. La vida de los esclavos y sus problemáticas se van resolviendo a lo largo del primer capítulo del libro donde se plantean los temas de masculinidad, o vida tras al post emancipación

En el segundo capítulo se aborda la esclavitud y la post emancipación en Martinica. Hace un recorrido por la historia de la isla, desde los inicios de la colonización francesa para llegar a la esclavitud e Martinica. Pese a que en el libro se tratan aspectos de la vida cotidiana de los esclavos no podemos catalogar el método de estudio de la vida cotidiana, el trabajo no puede ser catalogado como de estudios de la vida cotidiana. La cotidianeidad sirve para acercarse a la realidad de los esclavos y los ex esclavos. Cabe destacar el apartado dedicado a la revolución haitiana que si bien no afectó de forma directa durante esos años a la isla si hubo repercusiones a partir de la época napoleónica. Los esclavos de algunas plantaciones llevaron a cabo levantamientos contra las nuevas imposiciones de Napoleón, es interesante encuadrar este apartado dentro de las repercusiones que pudo tener la revolución haitiana, que no la revolución francesa en el Caribe, más en el caso de Martinica que quedó bajo el dominio de Francia. 
Ulrike Smieder dedica un apartado a la religión y esclavitud, uno de los temas que menos se han tratado pero que tienen una gran importancia dentro de las relaciones entre amos y esclavos. La religión es otro de los aspectos que estaban presentes tanto en Martinica como en Cuba fue otra de las formas de sometimiento de los esclavos, los misioneros tenían que dirigir la catequesis dos veces por semana, administrar los sacramentos y controlara la vida espiritual de los esclavos, este control no sólo servía para llevara a cabo el proceso evangelizador sino que inducía al esclavo a la sumisión, a la aceptación de su realidad y pretendía el control de las sublevaciones, que no eran del agrado de Dios.

Es importante la preocupación de la iglesia por la formación, no sólo de los esclavos sino también de los libres, se abrieron 5 escuelas par gente de color, dedicados a la formación de adultos, que según los colonos eran "gente sin creencias ni ley". Sin embargo pese a la animalización de los esclavos por parte de los propietarios, mantenían la catequización como un elemento más del control social.

En este segundo capítulo hay un apartado dedicado a la legislación, no hay que olvidar que la corona francesa dictó el llamado código negro en 1685 para regular la vida y las relaciones entre esclavos y propietarios, este código tenía una fuerte influencia del derecho romano, en el código se obligaba a los propietarios a educar a los esclavos en la religión católica y se prohibía a los protestantes el derecho a la propiedad de esclavos. Entre otras cosas el código negro recogía la condición de los nacidos, así de madre esclava y padre libre el niño era esclavo propiedad del dueño de la madre, sin embargo si el padre era esclavo pero la madre libre el nacido era libre.

Así mismo regulaba la condición de los nacidos del concubinato entre blancos y negras, algo que fue no poco frecuente en Martinica. El código negro francés regulaba, el descanso, la alimentación y el vestido de los esclavos, era un corpus legal exhaustivo que al menos de forma teórica, pretendía proteger la vida de los esclavos.

A partir del XIX la regulación cambió, se humanizó en parte, y se fueron admitiendo situaciones de hecho, de manera que la preparación para la abolición definitiva de la esclavitud se puso en marcha para aminorar los efectos de la emancipación entre los propietarios. 
La emancipación se produjo en Martinica por el movimiento de las élites, tanto, civiles como algunos movimientos católicos abolicionistas y no por la presión popular como se dio en el Reino Unido.

Tras el recorrido por Martinica la autora inicia su trabajo sobre Cuba con la misma estructura y apartados de manera que el lector puede ir sacando sus propias conclusiones sobre los sistemas esclavistas en las dos islas y sobre las diferencias estructurales de cada territorio.

Se presenta una buena cantidad de fuentes primarias tanto de archivos cubanos como españoles y franceses con un análisis profundo y riguroso de las mismas.

El libro se cierra con 44 páginas de bibliografía que recoge, prácticamente, todo lo que se ha escrito sobre cada uno de los capítulos que lo componen. Estamos ante un excelente trabajo en el que se analizan las problemáticas de la post emancipación comparando dos espacios, que habitualmente no se comparan, Cuba y Martinica, y no Cuba Estados Unidos, que en parte se ha trabajado, lo que supone un aliciente más para su lectura.

El trabajo de Ulrike Schmieder es riguroso, profundo y muestra las diferencias tanto de los sistemas coloniales como de los modelos esclavistas que se dieron en el Caribe colonial peor a la vez nos está enseñando cómo las diferencias de modelo de explotación, las diferentes políticas de cada una de las metrópolis tenían como fin el mismo objetivo la sobre explotación de la mano de obra esclava y la negación de la humanidad del otro. De nuevo los esclavistas consideran y definen al salvaje, a través del espejo. Las ideologías denigratorias, el salvajismo aplicado al otro no era sino el reflejo de la inhumanidad de los propietarios. 